\title{
RANCANG BANGUN ALAT PENGERING ECENG GONDOK UNTUK BAHAN KERAJINAN TANGAN (MENGGUNAKAN METODE TUNING CONTROLLER CHIEN REGULATOR I DAN CHIEN SERVO I)
}

\author{
Irianto $^{1)}$, Epyk Sunarno ${ }^{2)}$, Aqidah Ahya Nurlaily ${ }^{3)}$. \\ 1,2,3 Teknik Elektro Industri, Politeknik Elektronika Negeri Surabaya (PENS) \\ ${ }^{1)}$ Irianto@pens.ac.id, ${ }^{2}$ epyk@pens.ac.id, ${ }^{3)}$ aqidahahya96@gmail.com
}

\begin{abstract}
Hyacinth is a plant that can be utilized for the manufacture of various types of handicrafts, such as bags, sandals, souvenirs, and other furniture that has high art. In the process of making hyacinth crafts, it is considered in the process of drying. During this time, the hyacinth drying process still using conventional methods, which use solar energy which is dependent on weather conditions. Conventional drying methods relatively need long time, ie 7-10 days. So, that was designed hyacinth dryer that is not dependent on the weather and can be controlled with temperature sensors and weight sensor depend its set point. Hyacinth dryers use heater, blower and air circulation fan. The controller of the drying machine is Microcontroller ATMega 16 with PI Controll methods Tuning Controller Chien Regulator I with $\mathrm{Kp}=4,55$ and $\mathrm{Ki}$ $=0,3$ and Tuning Controller Chien Servo I $K p=2,65$ and $K i=0,156$. Hyacinth drying with a dryer need time shorter than using the conventional drying method, ie 12 hours with stabil temperature $60^{\circ} \mathrm{C}$. With this dryer can dry 30 stems of hyacinth with initial weight $500 \mathrm{~g}$ become dry hyacinth with weight $\pm 60 \mathrm{~g}$. Depends on the result of laboratory test, hyacint with dryer produce fiber content, water content, and ash content that good enough.
\end{abstract}

Keywords: Hyacinth, Mikrokontroller ATMega 16, Tuning Controller Chien Regulator I, Tuning Controller Chien Servo I

\section{PENDAHULUAN}

Pada saat ini, serat eceng gondok merupakan salah satu material natural fibre yang secara ilmiah pemanfaatannya masih bisa dikembangkan. Pada saat ini serat eceng gondok banyak sekali digunakan dalam industri-industri mebel dan kerajinan rumah tangga. Namun pada proses pengolahannya, terdapat proses pengeringan yang dilakukan dengan bantuan energi matahari yang masih membutuhkan waktu yang cukup lama, yaitu sekitar 7-10 hari, dan masih bergantung pada kondisi cuaca.

Untuk menjawab permasalahan di atas maka dengan dasar ini diciptakanlah suatu rancang bangun alat untuk membantu mengeringkan eceng gondok sebagai bahan baku kerajinan tangan. Alat ini berbasis mikrokontroler, dengan setting temperatur yang disesuaikan dengan suhu yang sesuai untuk pengeringa eceng gondok. Terdapat sensor berat dan sensor suhu yang digunakan untuk mendeteksi jika eceng gondok sudah ada pada kondisi kering. Dengan adanya teknologi ini diharapkan proses produksi kerajinan tangan eceng gondok menjadi lebih cepat dan dapat menghasilkan produk yang lebih banyak.

\section{METODE PENELITIAN}

Perancangan dan pembutan penelitian ini berpatokan pada blok diagram sistem serta alur kerja dari blok diagram. Gambar 1 meunjukkan gambaran umum sistem pengering eceng gondok yang akan dibuat.

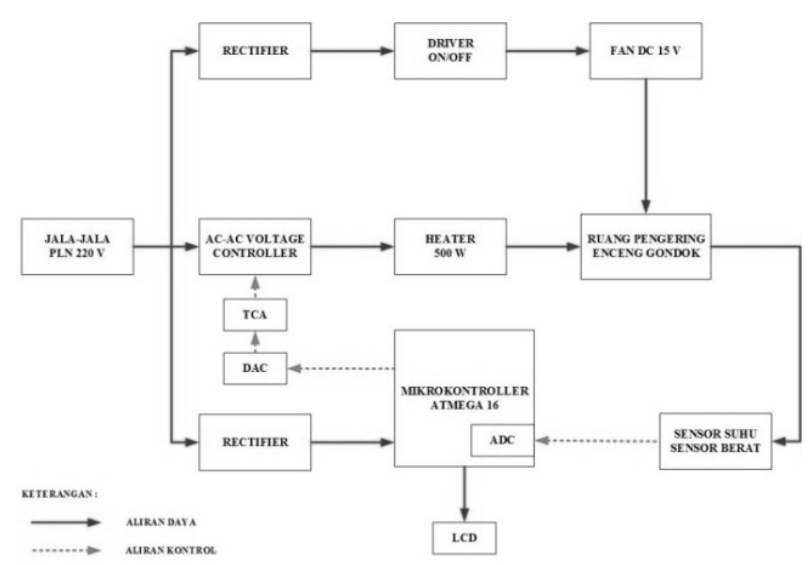

Gambar 1. Blok Diagram Sistem 
Pada penelitian ini, target yang diharapkan yaitu alat dapat menghasilkan eceng gondok kering sesuai dengan waktu yang lebih cepat dari metode konvensional. Untuk memperoleh hasil berupa eceng gomdok yang benar-benar kering, maka suhu pada inkubator pengering dijaga agar tetap konstan sebesar $60^{\circ} \mathrm{C}$. Untuk menjaga agar suhu pada ruangan pengering tetap konstan, maka pada alat ini menggunakan metode PI controller dengan tuning controller chien regulator $I$ dan chien servo $I$. PI controller digunakan untuk mengontrol tegangan input heater yang berasal dari $A C-A C$ voltage controller. Feed back untuk PI controller ini berasal dari sensor suhu LM35.

Prinsip kerja secara umum dari alat ini adalah sistem akan $O N$ ketika sambungan listrik dihubungkan ke jala-jala PLN 220 V. Sumber listrik yang digunakan untuk menyuplai heater yang telah dikendalikan tegangannya oleh AC AC Voltage Controller. Panas yang dihasilkan oleh heater kemudian didistribusikan oleh kipas agar rata keseluruh ruangan pemanas. Selain itu, terdapat kipas yang lainnya yang digunakan untuk mensirkulasikan udara sisa dari proses pengeringan. Kemudian terdapat sensor suhu (LM 35) yang digunakan untuk mengetahui nilai suhu udara di ruang pemanas yang ditempatkan di dalam inkubator, serta loadcell yang digunakan untuk mendeteksi berat eceng gondok yang telah kering. Hasil pembacaan sensor suhu kemudian akan dikirim menuju Atmega 16 untuk diolah pada mikrokontroler. Hasil olahan data akan dilanjutkan menuju DAC (digital analog converter) dan menjadi input TCA 785 untuk mengatur sudut penyulutan pada $A C-A C$ voltage controller.

Berikut dasar teori dari komponen penyusun serta metode pada penelitian ini.

\subsection{DAC (Digital to Analog Converter) R-2R}

Digital to Analog Converter (DAC) adalah rangkaian yang berfungsi mengubah kode digital 0x00 sampai 0xFF menjadi sinyal analog berupa tegangan 0 sampai 12 volt. Dimana keluaran dari rangkaian DAC ini masuk ke kaki 11 rangkain TCA785. Jumlah bit DAC secara keseluruhan adalah 255. Saat $\mathrm{DAC}=0$ TCA akan memiliki pulsa yang utuh, jika nilai DAC semakin dibesarkan maka pulsa yang dihasilkan TCA akan semakin mengecil, dengan kata lain nilai DAC berkebalikan dengan pulsa yang dihasilkan TCA. Nilai DAC ini akan memberi nilai penyulutan pulsa pada rangkaian TCA 785 yang akan digunakan sebagai trigger SCR pada rangkaian $A C-A C$ voltage controller. Pada rangkaian ini digunakan 18 resistor yang masing-masing bernilai $10 \mathrm{k} \Omega$.

\subsection{Rangkaian TCA 785}

Rangkaian kontrol TCA785 digunakan untuk megontrol sudut penyulutan pada rangkaian $A C-A C$ Voltage Controller, antara $0^{\circ}$ $-180^{\circ}$ pada sumber tegangan AC $220 \mathrm{~V}$. Rangkaian TCA785 ini dapat di kontrol secara manual (menggunakan potensio) atau dapat juga menggunakan mikrokontroler. Untuk penyearah terkontrol, 1 fasa siklus positif dengan siklus negatif berbeda $180^{\circ}$ maka akan dihasilkan sebuah pulsa penyalaan yang memiliki perbedaan fasa sebesar $180^{\circ}$.

IC TCA785 memerlukan sumber tegangan antara $8 \mathrm{~V}-18 \mathrm{~V}$, frekuensi kerja $10 \mathrm{~Hz}-50 \mathrm{~Hz}$ dengan temperatur kerja antara $25^{\circ} \mathrm{C}-80^{\circ} \mathrm{C}$.

Pada IC TCA785 memiliki beberapa pin, pin yang digunakan sebagai masukkan tegangan sinkronisasi (Vsync) dari pin 5 yang membentuk gelombang sinusoidal dengan penggunaan resistor $100 \mathrm{k} \Omega$ sebagai pembatas arus untuk mendapatkan arus masuk ke IC TCA 785 yang sesuai dengan datasheet dari IC TCA 785. Pada pin 11 digunakan sebagai masukkan untuk tegangan referensi sudut penyalaan, sedangkan pada pin 10 merupakan bentuk gelombang tegangan yang berupa gigi gergaji. Perpotongan antara gelombang referensi penyalaan dengan gelombang gigi gergaji terdapat pada pin 14 untuk gelombang yang bekerja pada daerah kerja negatif, dan pin 15 untuk gelombang yang bekerja pada daerah kerja positif.

\subsection{Rangkaian $A C$ - $A C$ voltage controller}

AC-AC voltage controller adalah konverter yang mengontrol tegangan, arus, dan daya rata-rata yang dikirim ke beban $\mathrm{AC}$ dari sumber AC. Komponen utama dari $a c a c$ voltage controller adalah TRIAC atau thyristor (SCR) yang dipasang secara anti-paralel. Skema pensakelaran dari ac ac voltage controller ada dua, yang pertama dengan phase control, pensakelaran berlangsung setiap siklus sumber, dimana gelombang tegangan dari sumber ke beban akan terhapus setiap siklusnya. Skema pensakelaran yang kedua adalah dengan integral cycle, dimana tegangan output pada beban akan terhapus untuk beberapa siklus. 
Rangkaian AC voltage controller ditunjukkan pada Gambar 2 dibawah.

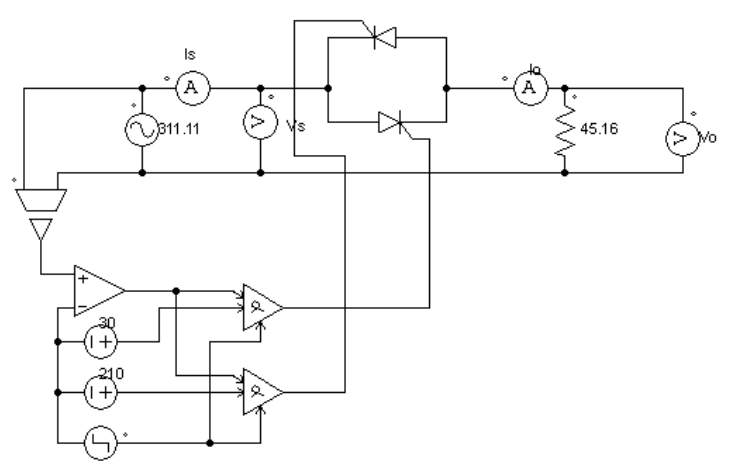

Gambar 2. Rangkaian AC-AC Voltage Controller

\subsection{Kontrol PI}

Gabungan aksi kontrol proporsional dan aksi kontrol integral membentuk aksi kontrol proporsional plus integral ( Kontroller PI ). Gabungan aksi ini mempunyai keunggulan dibandingkan dengan masing-masing penyusunnya. Keunggulan utamanya adalah diperolehnya keuntungan dari masing-masing aksi kontrol dan kekurangan aksi kontrol yang satu dapat diatasi. Dengan kata lain elemenelemen controller P dan I secara keseluruhan bertujuan untuk mempercepat reaksi sebuah sistem dan menghilangkan offset. Untuk memperoleh nilai $\mathrm{Kp}$ dan $\mathrm{Ki}$ yang tepat pertama-tama harus ditentukan karakteristik time respond dari plan secara uncontrolled. Secara praktikum untuk menentukan karakteristik time respond diperlukan data suhu heater hasil baca LM35, waktu yang dibutuhkan, nilai ADC dari LM35, dan besar tegangan LM35 yang diinput ke mikrokontroler.

Model proses self regulating adalah model yang paling umum dijumpai di industri proses. Model ini hampir muncul pada setiap kasus pengontrolan praktis, seperti pengontrolan temperatur pada sistem heat exchanger, pengontrolan level fluida pada sistem tangki penampung, dan sebagainya. Model self regulating process pada dasarnya dapat didekati oleh sebuah model matematis FOPDT (First Order Plus Dead Time) yang hanya dicirikan oleh tiga buah parameter berikut, yaitu:

- $\mathrm{K}=$ Gain statis proses (Process static gain)

- $\mathrm{L}=$ Keterlambatan transportasi proses (Process Transport Delay)
- $\tau=\mathrm{T}=$ Tetapan waktu proses (Process Time Constant)

Untuk tujuan analisa dan perancangan (terutama juga untuk kemudahan melakukan uji simulasi dengan Simulink), persamaan diferensial yang menggambarkan perilaku proses diatas secara umum dapat dipresentasikan kedalam bentuk fungsi alih proses denga persaman 1 berikut:

$\mathrm{H}(\mathrm{s})=\frac{\boldsymbol{p} v(s)}{\boldsymbol{c o}(s)}=\frac{\boldsymbol{K}}{\boldsymbol{T} s+1} \mathrm{e}^{-\mathrm{sL}}$

Dengan:

$\mathrm{H}(\mathrm{s})$ : fungsi alih kontrol proses FOPDT

$\mathrm{pv}(\mathrm{s})$ : transformasi Laplace deviasi output proses

co(s) : transformasi Laplace deviasi output kontroler (input proses)

s : variabel Laplace

Gambar 3 dibawah menunjukkan diagram simulasi FOPDT yang digunakan di Matlab

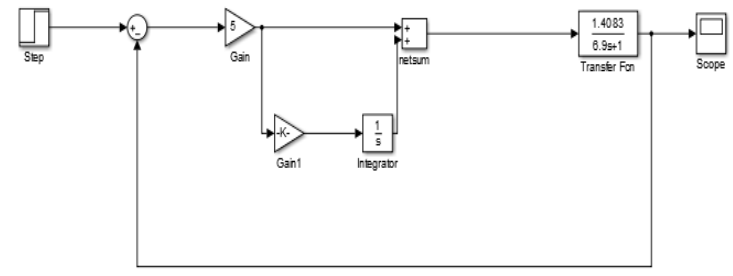

Gambar 3. Diagram Simulasi FOPDT

Untuk metode tuning yang digunakan pada kontroller PI ini adalah Chien Regulator 1 dan Chien Servo 1. Metode Controller Chien Regulator I dan Chien Servo I ini memiliki spesifikasi yaitu:

- $0 \%$ overshoot

- $0,11<\frac{L}{T}<1$

Pada Chien Regulator I, untuk mendapatkan nilai parameternya menggunakan rumus :

$$
\begin{aligned}
\mathrm{Kp} & =\frac{0,6 T}{K \times L} \\
\mathrm{Ki} & =\frac{K p}{\tau \mathrm{i}} \\
\tau \mathrm{i} & =4 \mathrm{~L}
\end{aligned}
$$

Sedangkan pada Chien Servo I, untuk mendapatkan nilai parameternya menggunakan rumus: 


$$
\begin{aligned}
& \mathrm{Kp}=\frac{0,35 T}{K \times L} \\
& \mathrm{Ki}=\frac{K p}{\tau \mathrm{i}} \\
& \tau \mathrm{i}=1,17 \mathrm{~T}
\end{aligned}
$$

Sedangkan pada Ziegler Nichols digunakan sebagai pembanding, untuk mendapatkan nilai parameternya menggunakan rumus:

$$
\begin{aligned}
& \mathrm{Kp}=\frac{0,9 T}{K \times L} \\
& \mathrm{Ki}=\frac{K p}{\tau \mathrm{i}} \\
& \tau \mathrm{i}=3,33 \mathrm{~L}
\end{aligned}
$$

\section{HASIL DAN PEMBAHASAN}

Dalam penelitian ini telah dilakukan beberapa pengujian. Sehingga didapatkan subbab hasil yang dibagi menjadi beberapa bagian. Bagian yang pertama yaitu hasil pengujian sistem kondisi openloop, sedangkan yang kedua adalah hasil pengujian sistem kondisi closeloop, dan yang terakhir adalah pengujian pengeringan eceng gondok.

\subsection{Pengujian Sistem Kondisi Openloop.}

Tahap selanjutnya yaitu pengujian dari sistem pemanasan dari ruang inkubator dengan kondisi open loop atau tanpa menggunakan kontrol agar diketahui bagaimana bentuk respon sistem. Adapun grafik pengujian sistem openloop yang dihasilkan adalah sesuai dengan Gambar 4.

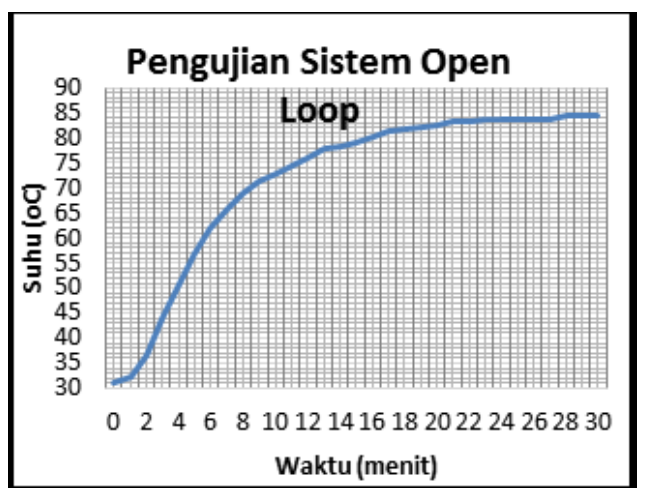

Gambar 4. Pengujian Sistem Open Loop

\subsection{Pengujian Sistem Kondisi Closeloop}

Setelah didapatkan respon sistem pada kondisi openloop, dilakukan penerapan kontrol PI dengan menggunakan metode tuning controller yang telah didesain sebelumnya untuk menjaga suhu pengeringan berada di nilai setpoint yang telah ditentukan yaitu sebesar $60^{\circ} \mathrm{C}$. Respon suhu pemanasan sistem ketika telah diberi tuning controller Chien Regulator I seperti pada Gambar 5 berikut.

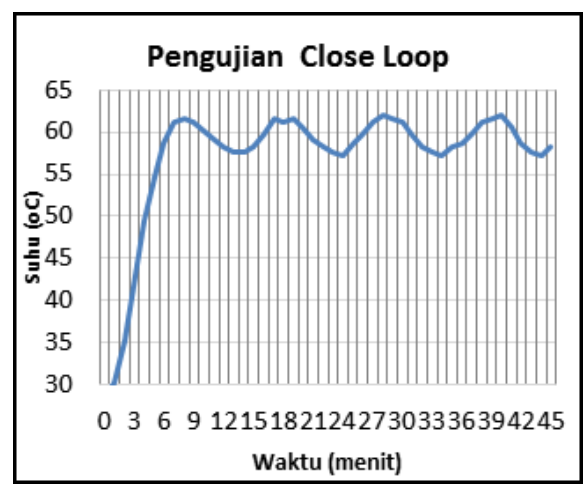

Gambar 5. Kurva karakteristik time respond heater terkontrol menggunakan Tuning Controller Chien Servo I

Berdasarkan grafik pada Gambar 5, tampak bahwa terdapat ripple suhu. Dengan set poin $60^{\circ} \mathrm{C}$, suhu terendah saat dikontrol adalah $57,185^{\circ} \mathrm{C}$, dan suhu tertinggi adalah $62,072^{\circ} \mathrm{C}$. Hal ini disebabkan karena ruang pemanas (mekanik) yang cukup besar sehingga menyebabkan suhu kurang stabil. KP yang digunakan adalah 4,55 dan Ki nya adalah 0,3. Sehingga apabila jadikan sebagai persentase, toleransi error untuk alat pengering ini adalah sebesar $\pm 5 \%$.

Sedangkan ketika menggunakan Tuning Controller Chien Servo I, kurva yang dihasilkan adalah seperti pada Gambar 6.

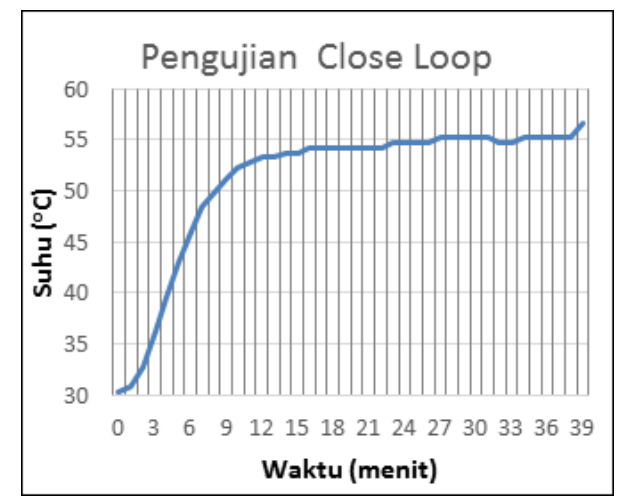

Gambar 6. Kurva karakteristik time respond heater terkontrol menggunakan Tuning

Controller Chien Servo I

Berdasarkan grafik pada Gambar 6, tampak bahwa suhu steady nya belum mencapai suhu set point. KP yang digunakan adalah 2,65 dan Ki nya adalah 0,156. Sehingga dalam pengeringan eceng gondok ini, metode tuning yang cocok untuk digunakan adalah metode tuning controller chien reguator $I$. 


\subsection{Pengujian dengan Eceng Gondok}

Pada tahap ini dilakukan proses pengujian alat yang telah diintegrasi dengan cara menggunakannya untuk mengeringkan eceng gondok. Eceng gondok yang dikeringkan adalah eceng gondok basah yang telah dibersihkan, dengan total 30 batang. Eceng gondok tersebut kemudian akan ditata di dalam kotak pengering. Gambar 7 menunjukkan alat pengering yang digunakan.

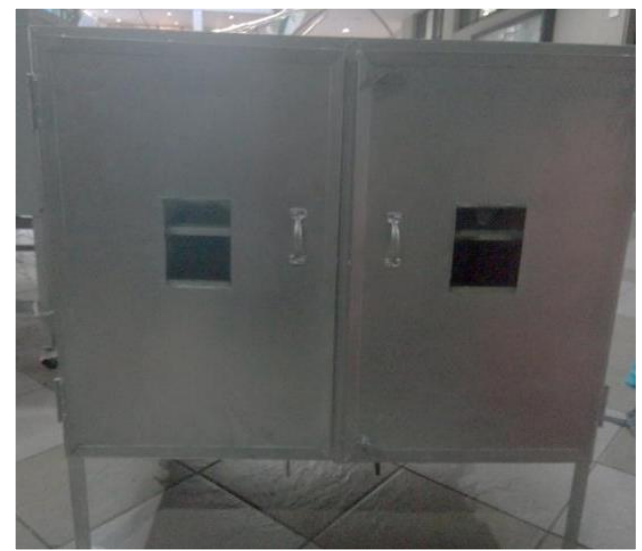

Gambar 7. Alat pengering eceng gondok yang digunakan

Setelah ditata di dalam alat pengering eceng gondok pun siap dikeringkan. Alat akan beroperasi selama \pm 12 jam. Selama pengoperasian tersebut suhu dari kotak pengering akan dikontrol dengan suhu set poin sebesar $60^{\circ} \mathrm{C}$. Metode tuning controller yang digunakan untuk mengeringkan eceng gondok ini adalah menggunakan metode tuning controller Chien Regulator I, dikarenakan suhu nya sudah mencapai set point. Berdasarkan hasil uji coba terintegrasi diperoleh hasil bahwa berat eceng gondok yang telah kering adalah sebesar 62gram dan berat awal eceng gondok basahnya adalah 532 gram. Gambar 8 menunjukkan gambar eceng gondok antara yang basah dan yang sudah kering.
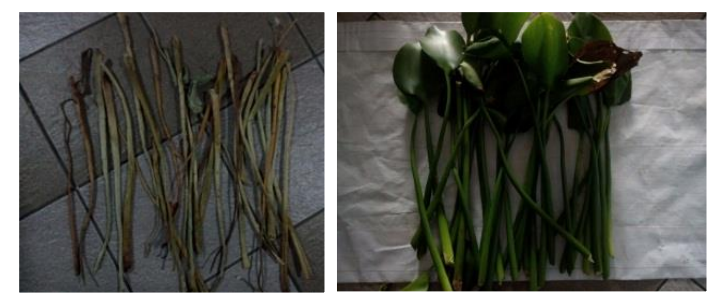

Gambar 8. Eceng gondok basah dan yang telah kering
Hasil dari proses pengeringan ini adalah berupa eceng gondok kering yang siap diolah menjadi berbagai kerajinan tangan. Berdasarkan hasil uji laboratorium dari BBLK (Balai Besar Laboratorium Kesehatan) Surabaya, dengan menggunakan alat pengering ini menghasilkan eceng gondok kering dengan kadar air, kadar serat, dan kadar abu yang dapat dikatakan cukup baik. Karena apabila dibandingkan dengan eceng gondok kering menggunakan metode konvensional, kandungan kadar tersebut tidak selisih jauh. Tabel 1 dibawah ini menunjukkan data pengujian kandungan pada masing-masing parameter dengan metode konvensional dan alat pengering.

Tabel 1. Pebandingan Kandungan Eceng Gondok Kering Metode Konvensional dan Menggunakan Alat Pengering

\begin{tabular}{|c|c|c|c|}
\hline No. & Parameter & $\begin{array}{c}\text { Metode } \\
\text { Konvensional } \\
(\%)\end{array}$ & $\begin{array}{c}\text { Dengan } \\
\text { Alat } \\
\text { Pengering } \\
(\%)\end{array}$ \\
\hline 1. & Kadar Abu & 4,75 & 4,62 \\
\hline 2. & Kadar Air & 16,45 & 15,96 \\
\hline 3. & Serat & 32,75 & 28,55 \\
\hline
\end{tabular}

\section{KESIMPULAN}

Dari hasil pengujian yang telah dilakukan dapat disimpulkan beberapa hal yaitu sebagai berikut:

1. Dari grafik pengujian alat pengering tanpa kontrol (open loop) dibutuhkan waktu 22,4 menit proses pemanasan untuk menuju suhu konstan sebesar $84,5^{\circ} \mathrm{C}$.

2. Pada proses pengeringan eceng gondok dengan alat pengering ini, metode tuning controller yang paling cocok adalah menggunakan tuning controller Chien Regulator I, dengan nilai $\mathrm{Kp}=4,55$ dan $\mathrm{Ki}=0,3$.

3. Inkubator pengering ini dapat bekerja dengan cukup baik. Hal ini dibuktikan dengan respon suhu yang berada di sekitar suhu set poin $60^{\circ} \mathrm{C}$ dari suhu awal sekitar $29^{\circ} \mathrm{C}$, dan untuk mencapai suhu set point ini membutuhkan waktu sekitar 7 menit .

4. Waktu yang dibutuhkan untuk mengeringkan eceng gondok menggunakan 
alat ini adalah sekitar 12 jam, lebih cepat dibandingkan dengan waktu pengeringan secara konvensional yaitu sekitar 10x7 jam (10 hari dimana per harinya dijemur selama 7 jam).

5. Dengan menggunakan metode tuning controller ini dimungkinkan terdapat nilai $\mathrm{Kp}$ dan $\mathrm{Ki}$ yang menghasilkan hasil yang lebih baik apabila diaplikasikan pada plant lainnya.

6. Berdasarkan hasil uji laboratium, pengeringan menggunakan alat pengering menghasilkan eceng gondok kering dengan kadar air, kadar serat, dan kadar abu yang cukup baik bila dibandingkan dengan pengeringan eceng gondok menggunakan metode konvensional.

\section{REFERENSI}

Atmel Corporation, Datasheet of ATMegal6. Atmel Corporation, hal 3

Bakhri, Mohammad Samsul. 2017: "Desain Pengering Eceng Gondok Tipe Batch Sumber Panas Gas Buang Dari Combined Heat and Power". Skripsi Teknik Mesin dan Biosistem, ITB

Kunto Purbono, Makhmudun Ainuri, Suryandono.2010:'Rancang Bangun Dan Uji Kelayakan Finansial Alat Pengering Mekanis Untuk Pemenuhan Pasokan Eceng Gondok (Eichhornia Crassipes) Sebagai Bahan Baku Kerajinan”.Agritech,Vol. 30, No. 2.

Putra, Rizki Dirgahaya. 2012:"Ekstraksi Serat Selulosa Dari Tanaman Eceng Gondok (Eischornia Crassipes) Dengan Variabel Pelarut". FT UI.

Rahayuningtyas, Ari, Aidil Haryanto, dan Rina Kumalasari. 2012: "Perancangan dan Uji Performasi Pengering Tipe Rak pada UKM Shan's Cap Rumoh Aceh". Prosiding UNISBA

Sari, Puspita Kurnia, Epyk Sunarno, S.ST.,M.T. dan Drs. Irianto M.T. 2016: "Rancang Bangun Alat Pengering Tahu Sebagai Bahan Baku Stik Tahu". Tugas Akhir D3 Jurusan Teknik Elektro Industri, PENS.

Setiawan, Iwan. "Kontrol PID untuk Proses Industri”. PT. Elex Media Kominfo, Jakarta.

Tumolva, T., J. Ortenero, M. Kubouchi. "Characterization and Treatment of Water Hyacinth Fibers For NFRP Composites" . The $19^{\text {th }}$ International Conference on Composite Materials. 
